\title{
Findings by SS-OCT and OCT-A in patients with sickle cell disease compared to healthy individuals
}

\section{Hallazgos de SS-OCT y OCT-A en pacientes con anemia de células falciformes comparados con individuos sanos}

\author{
Diego Bueso-Ponce ${ }^{1}$, Juan Unigarro ${ }^{1}$, Sofía Vidal', Carlos Salgado ${ }^{1}$, Enrique Ramos ${ }^{2}$, and \\ Carlos Abdala-Caballero ${ }^{1 *}$ \\ ${ }^{1}$ Department of Retina and Vitreous, Abdala-Figuerola ophthalmology group/Clínica Unidad Laser del Atlántico, Barranquilla; ${ }^{2}$ Department of \\ Epidemiology and Biostatistics, Universidad del Sinú, Cartagena. Colombia
}

\begin{abstract}
Purpose: To describe the findings in central macular thickness, mean macular thickness, central choroidal thickness, and foveal avascular zone at the superficial and deep retinal plexus, and to compare the results with a group of healthy subjects. Methods: Descriptive study about SS-OCT and OCT-A findings in 28 eyes (14 patients) with electrophoretic confirmation of sickle cell disease and 60 eyes (30 patients) without systemic or ocular disorders. Results: In the sickle cell disease group, median central macular thickness was $194 \mathrm{vs.} 229 \mu \mathrm{m}$ in the healthy subjects group $(p<0.0001)$. The area of the foveal avascular zone at the superficial plexus showed a median value of $0.347 \mathrm{vs.} 0.243 \mathrm{~mm}^{2}(p<0.0001)$ and at the deep capillary plexus of 0.461 vs. $0.321 \mathrm{~mm}^{2}$ in the sickle cell disease and healthy subjects groups, respectively $(p<0.0001)$. The comparative measures of mean macular thickness and central choroidal thickness did not reveal significant statistical differences between groups. Conclusions: Compared to a healthy control group, patients with sickle cell disease had a statistically significant lower central macular thickness and an enlarged foveal avascular zone at both the superficial and deep plexuses. SS-OCT and OCT-A are non-invasive imaging modalities that provide high resolution images that can be useful to detect anatomic and micro vascular alterations in patients with sickle cell disease.
\end{abstract}

Key words: Sickle cell disease. Optical coherence tomography angiography. Deep capillary plexus. Superficial capillary plexus. Swept source optical coherence tomography. Foveal avascular zone.

\section{Resumen}

Objetivo: Describir los cambios en el grosor macular central, el grosor macular promedio, el grosor coroideo central y el área de la zona avascular foveal en los plexos superficial y profundo de pacientes con anemia de células falciformes, $y$ comparar los resultados con un grupo de sujetos sanos. Método: Estudio descriptivo de hallazgos de tomografía de coherencia óptica swept source (SS-OCT) y de angiografía por tomografía de coherencia óptica (OCT-A) en 28 ojos de 14 pacientes con anemia de células falciformes confirmado por electroforesis y 60 ojos de 30 personas sanas sin antecedentes patológicos sistémicos ni oculares. Resultados: En el grupo de anemia de células falciformes la mediana del grosor macular central fue de $194 \mu \mathrm{m}$, frente a $229 \mu \mathrm{m}$ en el grupo de personas sanas $(p<0.0001)$. La mediana de zona avascular

Correspondence:

${ }^{*}$ Carlos Abdala

Cra 30, Corredor Universitario 1-850

Médica, Consultorio 812

Date of reception: $21-05-2020$

Barranquilla 081007, Colombia

E-mail: cabdala@ retinayvitreo.com
Date of acceptance: 12-08-2020

DOI: 10.24875/RMOE.M21000156 (http://creativecommons.org/licenses/by-nc-nd/4.0/).

Available online: 16-03-2021

Rev Mex Oftalmol (Eng). 2021;95(2):53-59

www.rmo.com.mx 
foveal en el plexo superficial del grupo de anemia de células falciformes fue de $0.347 \mathrm{~mm}^{2}$, frente a $0.243 \mathrm{~mm}^{2}$ en el grupo sano, y en el plexo vascular profundo la mediana fue de 0.461 frente a $0.321 \mathrm{~mm}^{2}$, respectivamente $(p<0.0001)$. Las medidas comparativas del grosor macular promedio y del grosor coroideo no demostraron diferencia estadísticamente significativa entre ambos grupos. Conclusiones: En comparación con el grupo de sanos, los pacientes con anemia de células falciformes presentaron diferencias estadisticamente significativas: menor grosor macular central y aumento del área de la zona avascular foveal en los plexos superficial y profundo. La SS-OCT y la OCT-A son modalidades de estudio no invasivo que proporcionaron imágenes de alta resolución que podrían ser útiles para detectar cambios anatómicos estructurales y microvasculares en ambos plexos en pacientes con anemia de células falciformes.

Palabras clave: Anemia de células falciformes. Angiografía por tomografía de coherencia óptica. Plexo capilar profundo. Plexo capilar superficial. Tomografía de coherencia óptica swept source. Zona avascular foveal.

\section{Introduction}

Sickle cell disease (SCD) is an autosomal recessive hemoglobinopathy characterized by the presence of hemoglobin $\mathrm{S}$ as a result of a specific mutation of amino acid, in which glutamic acid is replaced with valine at the sixth position of the $\beta$-globin chain ${ }^{1,2}$.

It was described in 1910 by Herrick in a West Indian patient $^{3}$. In Colombia it is considered an orphan disease and its incidence are 0.03/100,000 inhabitants ${ }^{4}$. It is estimated that 100,000 individuals are affected by the disease in the United States of America, and the prevalence is higher in the Middle East, the Mediterranean, Southwest Asia and sub-Saharan Africa ${ }^{5}$.

Ocular manifestations are common, but in many cases they are underdiagnosed. Blood viscosity, abnormal structure, and fragility of erythrocytes trigger hemolysis, recurrent vascular occlusions, and endothelial damage leading to ischemia of the retinal capillary network, which stimulates neovascularization or causes retinal atrophy².

For more than 40 years, fluorescein angiography has been the reference method for the study of retinal vascular anatomy in patients with $\mathrm{SCD}^{6,7}$. In general, peripheral findings predominate like ischemic zones in the macula, irregularity of the foveal avascular zone (FAZ), microaneurysms and flattening of the foveal excavation ${ }^{8}$.

The advent of swept-source optical coherence tomography angiography (SS-OCT) and optical coherence tomography angiography (OCT-A) has made it possible to study retinal vascular anatomy by generating high-resolution segmented images of the retinal superficial and deep plexuses ${ }^{9,10}$.

The purpose of this study is to describe the changes in central macular thickness (CMT), central choroidal thickness (CCT), average macular thickness (AMT) and the area of the superficial and deep FAZ in patients with SCD, and to compare the results with those of healthy people.

\section{Methods}

A descriptive study was carried out with a group of patients diagnosed with SCD and another group of healthy people, who were evaluated at the Clínica Unidad Laser del Atlántico in Barranquilla, Colombia. The approval of the institutional ethics committee was obtained, all participants signed the informed consent and the study adhered to the guidelines stipulated in the Declaration of Helsinki.

Patients with hemoglobin SC and SS confirmed by electrophoresis, without other systemic antecedents and without proliferative retinopathy were included in the SCD group. Patients with a history of arterial hypertension, diabetes mellitus, glaucoma, retinal vascular disease, vitreomacular traction, retinal detachment, a history of vitreoretinal surgeries, or poor-quality SSOCT and OCT-A images that did not allow reliable measurements were excluded. The other group included healthy people without a history of systemic or ocular disease, with ages similar to those of patients with SCD.

All patients underwent a complete ocular evaluation. The images were taken with the DRI OCT Triton Plus (Topcon Corporation, Tokyo, Japan) with SS-OCT technology and 3-D macular protocol, and $4.5 \times 4.5$ $\mathrm{mm}$ OCT-A with the same equipment. CMT, CCT and AMT were measured using the center circle of the ETDRS (Early Treatment Diabetic Retinopathy Study) grid incorporated in the software. The measurement of the FAZ was carried out manually and by a single operator, at the level of the superficial and deep vascular plexuses, with the colored template used to measure vascular density. The measurement of the area of the FAZ was outlined following the contour of the dark blue color that codes for a vascular density of $0 \%$ (Fig. 1).

In the entire selected population, the general variables, such as age and sex, were registered. The 
Table 1. General characteristics and comparison of results between the group with sickle cell disease and the control group of healthy subjects

\begin{tabular}{|c|c|c|c|}
\hline & $\operatorname{SCD}(n=28)$ & Healthy $(n=30)$ & $\mathbf{p}$ \\
\hline Age in years, median (IOR) & $21(15-28)$ & $27(23-30)$ & 0.0020 \\
\hline$<20$ years & $14(50.0)$ & $4(6.7)$ & $<0.0001$ \\
\hline $21-30$ years & $12(42.9)$ & $42(70.0)$ & 0.0148 \\
\hline $31-40$ & $0(0.0)$ & $0(0.0)$ & -- \\
\hline $41-50$ & $0(0.0)$ & $0(0.0)$ & -- \\
\hline $51-60$ & $2(7.1)$ & $14(23.3)$ & 0.0804 \\
\hline$>60$ & $0(0.0)$ & $0(0.0)$ & -- \\
\hline $\begin{array}{l}\text { Sex } \\
\text { Female } \\
\text { Male }\end{array}$ & $\begin{array}{l}18(64.3) \\
10(35.7)\end{array}$ & $\begin{array}{l}40(66.7) \\
20(33.3)\end{array}$ & 0.8262 \\
\hline $\begin{array}{l}\text { Results SS-OCT, mean (IOR) } \\
\text { Central macular thickness } \\
\text { Central choroidal thickness } \\
\text { Average macular thickness } \\
\text { Superficial FAZ } \\
\text { Deep FAZ }\end{array}$ & $\begin{array}{c}194(180-223) \\
281(220-319) \\
289(271-297) \\
0,347(0,266-0,452) \\
0,461(0,376-0,583)\end{array}$ & $\begin{array}{c}229(222-250) \\
292(220-333) \\
280(270-288) \\
0,243(0,198-0,305) \\
0,321(0,244-0,379)\end{array}$ & $\begin{array}{c}<0.0001 \\
0.4490 \\
0.0234 \\
<0.0001 \\
<0.0001\end{array}$ \\
\hline
\end{tabular}

IQR: interquartile range; SS-OCT: swept source-optical coherence tomography; FAZ: foveal avascular zone.

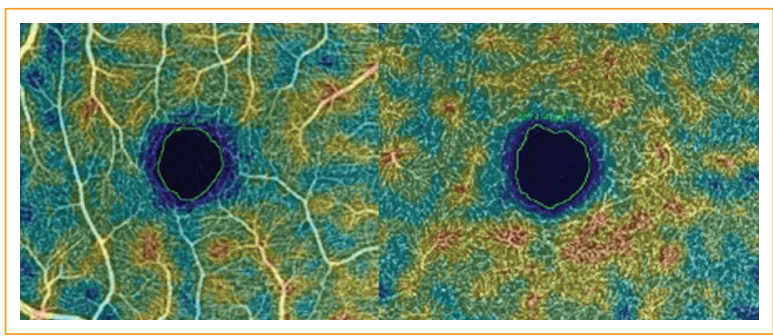

Figure 1. Manual measurement of the area of the foveal avascular zone at the level of the superficial and deep vascular plexuses in a healthy person. Using the vascular density map, the outline of the dark blue-black zone was traced, which corresponds to a vascular density of $0 \%$.

descriptive statistical analysis consisted of qualitative variables for absolute and relative frequencies estimation, while for the quantitative variables, central tendency measures like the median were obtained with their respective interquartile range (IQR) dispersion measure, used due to the non-parametric distribution of quantitative variables estimated by the Shapiro-Wilk test. Comparisons of thicknesses and measurements of SS-OCT and OCT-A between patients with SCD and healthy people were performed with the Mann Whitney $\mathrm{U}$ test, and a value of $\mathrm{p}<0.05$ was considered as a statistically significant difference.

\section{Results}

We included 88 eyes, 28 from 14 patients with SCD (five with hemoglobin SC and nine with hemoglobin SS) and 60 from 30 healthy people. The median age in the SCD group was 21 years (IQR: 15-28) and in the healthy group was 27 years (IQR: $23-30)(p=0.0020)$. Regarding the distribution by sex, $64.3 \%$ of the patients with SCD were men and in healthy people the proportion was of $66.7 \%(p=0.8262)$ (Table 1$)$.

When comparing the results of SS-OCT, the median of CMT in the SCD group was $194 \mu \mathrm{m}$ (IQR: 180-223), and in the healthy group was $229 \mu \mathrm{m}$ (IQR: 222-250) $(p<0.0001)$. CCT showed medians in the SCD and healthy groups of 281 and $292 \mu \mathrm{m}$, respectively $(\mathrm{p}=0.4490)$. AMT had a median of $289 \mu \mathrm{m}$ (IQR: 271-297) in the SCD group and of $280 \mu \mathrm{m}$ (IQR: $270-288)$ in the healthy group $(p=0.0234)$ (Fig. 2). The area of the superficial FAZ in the SCD group had a median of $0.347 \mathrm{~mm}^{2}$ (IQR: 0.2660 .452 ), while in the healthy group it was $0.243 \mathrm{~mm}^{2}$ (IQR: 0,198-0,305) $(p<0.0001)$. The same behavior was observed in the deep FAZ, which had a median of $0.461 \mathrm{~mm}^{2}$ in the SCD group and of $0.321 \mathrm{~mm}^{2}$ in the healthy group ( $p<0.0001$ ) (Fig. 3). In patients with SCD, the FAZ showed a greater enlargement at the level of the deep vascular plexus, which was demonstrated in a particular patient with a measurement of $0.869 \mathrm{~mm}^{2}$ (Fig. 4). 


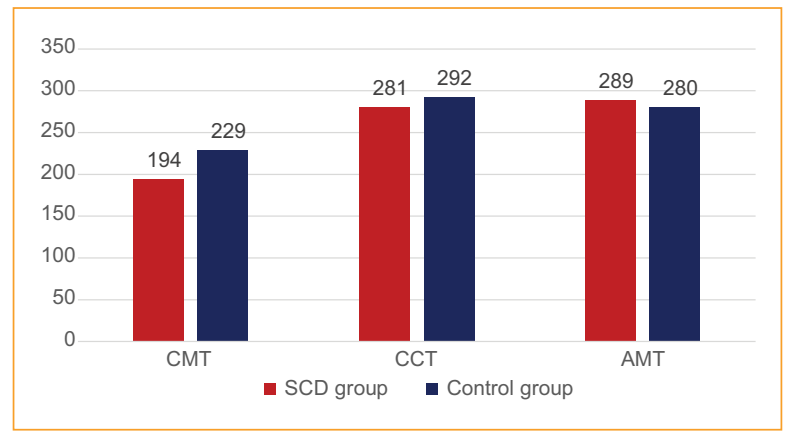

Figure 2. Comparison of central macular thickness (CMT), central choroidal thickness (CCT) and average macular thickness (AMT) in the group of patients with sickle cell disease (SCD) and in the control group of healthy people (microns).

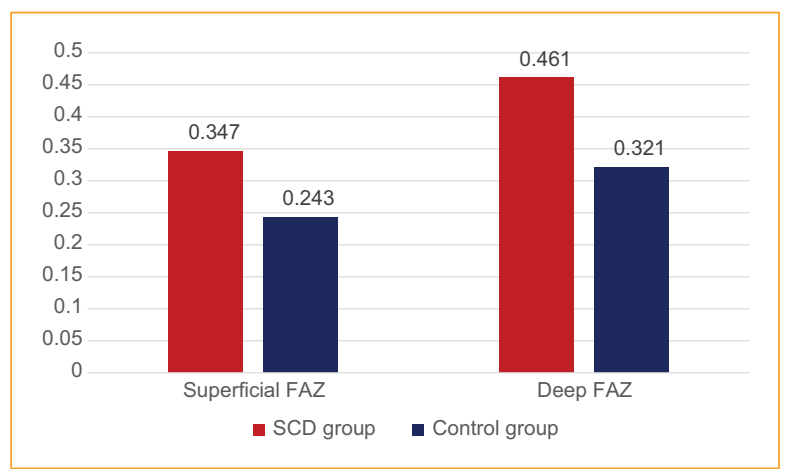

Figure 3. Comparison of the area of the foveal avascular zone (FAZ) at the level of the superficial and deep plexuses in the group of patients with sickle cell disease (SCD) and in the control group of healthy people $\left(\mathrm{mm}^{2}\right)$.

When analyzing the B-scan images of the SS-OCT along with the segmentation images of the vascular plexuses by OCT-A, in 10 of 28 eyes (35\%) of the SCD group, we identified areas of flattening of the foveal excavation, retinal atrophy temporal to the fovea and alteration of the parallelism of the retinal layers that correlated with focal zones of decreased vascular density, and areas classified by the equipment as non-perfusion areas (Fig. 5).

Regarding the functional status of the patients in the SCD group, uncorrected visual acuity (VA) was on average 20/25; when measuring pinhole VA, it was of 20/20 in eyes with a decreased VA (Table 2).

\section{Discussion}

To the best of our knowledge, this study is the first to use SS-OCT and OCT-A technology in patients with

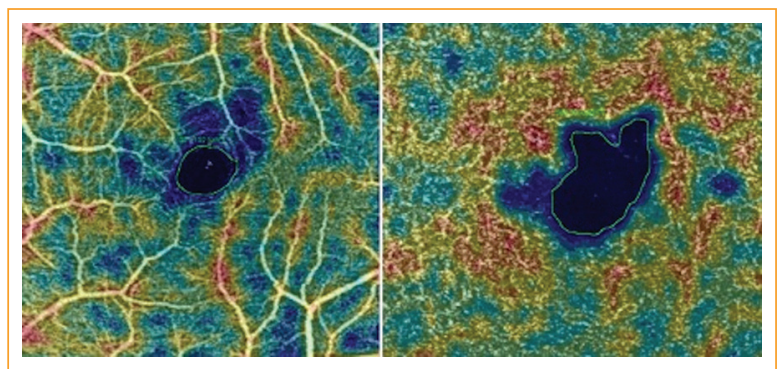

Figure 4. Comparison of the increased area of the deep foveal avascular zone compared to the superficial one.

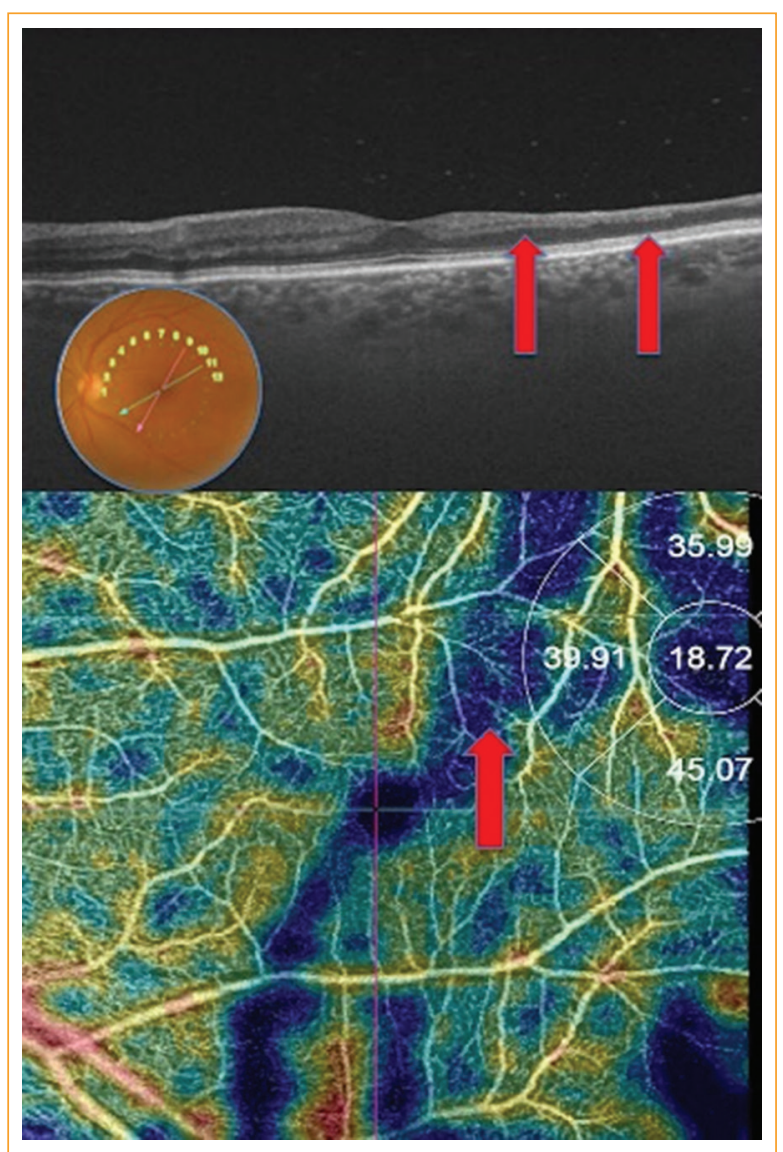

Figure 5. B-scan with the corresponding optical coherence tomography angiography image showing areas of loss of vascular density in the deep plexus associated with areas of retinal atrophy and thinning (red arrows).

SCD compared to healthy subjects in Latin America, since the vast majority of previously published studies used spectral-domain OCT (SD-OCT).

Our study revealed a decrease in CMT and an increase of the FAZ in patients with SCD compared to the healthy individuals, while CCT and AMT showed no 
Table 2. Sickle cell disease group: comparison between structural findings and visual acuity

\begin{tabular}{|c|c|c|c|c|c|c|c|}
\hline Patient & Age & Eye & СМТ (pm) & Superficial FAZ $\left(\mathrm{mm}^{2}\right)$ & Deep FAZ $\left(\mathrm{mm}^{2}\right)$ & UCVA & Pinhole VA \\
\hline \multirow[t]{2}{*}{1} & 54 & $\mathrm{OD}$ & 223 & 0.228 & 0.941 & $20 / 30$ & $20 / 20$ \\
\hline & & OS & 245 & 0.221 & 0.281 & $20 / 30$ & $20 / 20$ \\
\hline \multirow[t]{2}{*}{2} & 28 & OD & 178 & 0.362 & 0.525 & $20 / 20$ & \\
\hline & & os & 174 & 0.391 & 0.867 & $20 / 20$ & \\
\hline \multirow[t]{2}{*}{3} & 8 & $\mathrm{OD}$ & 221 & 0.243 & 0.433 & $20 / 30$ & $20 / 20$ \\
\hline & & OS & 205 & 0.271 & 0.278 & $20 / 30$ & $20 / 20$ \\
\hline \multirow[t]{2}{*}{4} & 30 & $\mathrm{OD}$ & 210 & 0.531 & 0.64 & $20 / 25$ & $20 / 20$ \\
\hline & & os & 192 & 0.551 & 0.618 & $20 / 25$ & $20 / 20$ \\
\hline \multirow[t]{2}{*}{5} & 8 & $O D$ & 170 & 0.329 & 0.379 & $20 / 25$ & $20 / 20$ \\
\hline & & OS & 220 & 0.354 & 0.411 & $20 / 25$ & $20 / 20$ \\
\hline \multirow[t]{2}{*}{6} & 27 & $\mathrm{OD}$ & 193 & 0.288 & 0.373 & $20 / 25$ & $20 / 20$ \\
\hline & & os & 196 & 0.274 & 0.367 & $20 / 25$ & $20 / 20$ \\
\hline \multirow[t]{2}{*}{7} & 15 & $\mathrm{OD}$ & 180 & 0.375 & 0.402 & $20 / 20$ & \\
\hline & & os & 175 & 0.427 & 0.572 & $20 / 25$ & $20 / 20$ \\
\hline \multirow[t]{2}{*}{8} & 25 & $\mathrm{OD}$ & 171 & 0.262 & 0.352 & $20 / 20$ & \\
\hline & & os & 180 & 0.223 & 0.509 & $20 / 20$ & \\
\hline \multirow[t]{2}{*}{9} & 9 & $\mathrm{OD}$ & 180 & 0.341 & 0.511 & $20 / 25$ & $20 / 20$ \\
\hline & & os & 183 & 0.332 & 1.686 & $20 / 25$ & $20 / 20$ \\
\hline \multirow[t]{2}{*}{10} & 18 & $\mathrm{OD}$ & 185 & 0.25 & 0.334 & $20 / 20$ & \\
\hline & & OS & 185 & 0.228 & 0.367 & $20 / 20$ & \\
\hline \multirow[t]{2}{*}{11} & 25 & $\mathrm{OD}$ & 222 & 0.314 & 0.411 & $20 / 25$ & $20 / 20$ \\
\hline & & os & 223 & 0.359 & 0.451 & $20 / 25$ & $20 / 20$ \\
\hline \multirow[t]{2}{*}{12} & 28 & $\mathrm{OD}$ & 230 & 0.357 & 0.595 & $20 / 20$ & \\
\hline & & OS & 191 & 0.551 & 0.754 & $20 / 20$ & \\
\hline \multirow[t]{2}{*}{13} & 16 & $\mathrm{OD}$ & 244 & 0.477 & 0.462 & $20 / 20$ & \\
\hline & & OS & 241 & 0.492 & 0.53 & $20 / 20$ & \\
\hline \multirow[t]{2}{*}{14} & 16 & $\mathrm{OD}$ & 244 & 0.498 & 0.479 & $20 / 25$ & $20 / 20$ \\
\hline & & OS & 241 & 0.495 & 0.46 & $20 / 25$ & $20 / 20$ \\
\hline
\end{tabular}

UCVA: uncorrected visual acuity; CMT: central macular thickness; OD: right eye; OS: left eye; FAZ: foveal avascular zone.

statistically significant difference between groups. Additionally, a flattening of the foveal excavation was identified, with retinal atrophy temporal to the fovea associated with areas of decreased vascular density and no focal perfusion.

In 2018, Jung, et al. ${ }^{11}$ compared the findings by SDOCT and SS-OCT in a patient with a diagnosis of SCD. They demonstrated perifoveolar and parafoveolar temporal and nasal retinal thinning, with areas of loss of vascular density in the superficial and deep plexuses. SS-OCT and OCT-A allowed a better visualization of the perifoveal and parafoveal areas to differentiate between ischemic and perfused areas. A greater loss of vascular density was observed in the FAZ at the level of the deep vascular plexus, which correlates with our findings in patients with SCD. 
Lim and $\mathrm{CaO}^{8}$ analyzed 513 eyes using SD-OCT in patients with SCD and reported an average CMT of 253 $\mu \mathrm{m}$, compared to $262.8 \mu \mathrm{m}$ in a healthy control group $(p=0.002)$. In our study, the median CMT was statistically lower; $192 \mu \mathrm{m}$ in the SCD group and $229 \mu \mathrm{m}$ in the control group.

In different studies published by Hoang, et al. ${ }^{9}$ and Han, et al. ${ }^{12}$ using SD-OCT, a decrease in CMT was demonstrated as well as flattening and enlargement of the foveal avascular zone and retinal atrophy corresponding to areas where vascular density was lost. They attributed these findings to ischemia of the foveal capillary network secondary to vascular occlusions. In our study, the OCT-A and the B-scan of the SS-OCT allowed to precisely identify the areas of ischemia and loss of vascular density in the deep vascular plexus in 10 patients, which corresponded to areas of foveal flattening, temporal retinal atrophy and reduction of CMT.

Alam, et al. ${ }^{13}$ showed that the average area of the superficial and deep FAZ increased by $53 \%$ and $52 \%$, respectively, in 36 eyes of patients with SCD compared with a control group. In our study, the difference between both groups was statistically significant, and the deep plexus was the one most affected, with a median difference of $140 \mu \mathrm{m}$ between the SCD group and the control group.

Mathew, et al. $^{10}$ found by SD-OCT a decrease in choroidal thickness in patients with SCD; they attributed this difference to a decreased flow velocity and sickle cell decreased deformability. However, they did not show a correlation with focal retinal thinning, which could indicate that choroidal changes are independent of microvascular macular changes. Our study found no statistically significant difference in terms of CCT and AMT between both groups.

According to the findings described in the structural anatomical evaluation and pinhole VA in the SCD group, we could theorize that the structural damage around the FAZ in both plexuses is early and incipient, without affecting VA.

Retinal sensitivity needs to be confirmed with microperimetry and macular visual field tests to determine functional damage from these findings.

We consider that the main limitations of the study were the small sample studied, that there was no correlation of the anatomical findings with best-corrected VA or with fluorescein angiography, and that the healthy control group had no homogeneous ages compared to the SCD group. Currently, OCT-A has limitations inherent to its technology, since it does not allow to assess the extreme periphery and is subject to artifacts that could interfere with the analysis of the results. In addition, the FAZ measurement was carried out manually, which could generate variations as it was operator-dependent.

The described findings warrant the evaluation of the relationship between the increase in the area of the FAZ in both vascular plexuses, the decreased CMT, and its functional sequelae on VA. It is necessary that patients diagnosed with SCD receive periodic follow-up to identify and prevent a progression of retinopathy. As technology advances, SS-OCT and OCT-A could be very useful in developing protocols for the diagnosis and follow-up of patients with $S C D$, especially young asymptomatic patients.

\section{Conclusion}

Compared with the healthy control group, the SCD group had a lower CMT and an increase in the area of the FAZ at the level of the superficial and deep plexuses, which were statistically significant, while CCT and AMT showed no changes. The OCT-A segmentation images made it possible to identify areas of retinal atrophy associated with areas of loss of vascular density and non-perfusion. SS-OCT and OCT-A are novel non-invasive tests that may be useful to detect quantitatively, microangiopathic, and structural changes in patients with SCD maculopathy. Larger, long-term studies are needed to demonstrate the relationship between changes in FAZ, CCT, AMT, and CMT.

\section{Funding}

The present study did not receive sponsorship or financial support for its development, authorship and publication.

\section{Conflicts of interest}

The authors declare no conflicts of interest.

\section{Ethical disclosures}

Protection of human and animal subjects. The authors declare that no experiments were performed on humans or animals for this study.

Confidentiality of data. The authors declare that they have followed the protocols of their work center on the publication of patient data.

Right to privacy and informed consent. The authors have obtained the written informed consent of the 
patients or subjects mentioned in the article. The corresponding author is in possession of this document.

\section{References}

1. Stuart M, Nagel R. Sickle-cell disease. Lancet. 2004;364:1343-60.

2. Elagouz M, Jyothi S, Gupta B, Sivaprasad S. Sickle cell disease and the eye: old and new concepts. Surv Ophthalmol. 2010;55:359-77.

3. Do B, Rodger D. Sickle cell disease and the eye. Curr Opin Ophthalmol. 2017;28:623-8

4. Misnaza Castrillón SP. Drepanocitosis en Colombia: análisis de la notificación como enfermedad huérfana o rara al sistema de vigilancia en salud pública, 2016 y 2017; 23:1-13. Disponible en: https://www.ins.govco/

5. Hassell K. Population estimates of sickle cell disease in the U.S. Am J Prevent Med. 2010;38:S512-21.

6. Stevens T. Sickling hemoglobinopathies. Arch Ophthalmol. 1974;92:455

7. Ryan S. Occlusion of the macular capillaries in sickle cell hemoglobin $C$ disease. Am J Ophthalmol. 1974;77:459-61.
8. Lim J, Cao D. Analysis of retinal thinning using spectral-domain optical coherence tomography imaging of sickle cell retinopathy eyes compared to age- and race-matched control eyes. Am J Ophthalmol. 2018;192:229-38.

9. Hoang Q, Chau F, Shahidi M, Lim J. Central macular splaying and outer retinal thinning in asymptomatic sickle cell patients by spectral-domain optical coherence tomography. Am J Ophthalmol. 2011;151:990-4.e1.

10. Mathew R, Bafiq R, Ramu J, Pearce E, Richardson M, Drasar E, et al. Spectral domain optical coherence tomography in patients with sickle cell disease. Br J Ophthalmol. 2015;99:967-72.

11. Jung J, Chen M, Frambach C, Rofagha S, Lee S. Spectral domain versus swept source optical coherence tomography angiography of the retinal capillary plexuses in sickle cell maculopathy. Retin Cases Brief Rep. 2018;12:87-92.

12. Han I, Tadarati M, Scott A. Macular vascular abnormalities identified by optical coherence tomographic angiography in patients with sickle cell disease. JAMA Ophthalmol. 2015;133:1337.

13. Alam M, Thapa D, Lim J, Cao D, Yao X. Quantitative characteristics of sickle cell retinopathy in optical coherence tomography angiography. Biomed Opt Express. 2017;8:1741-53. 